\title{
Swedish Response to COVID-19
}

\author{
Johan Carlson ${ }^{1}$; Anders Tegnell ${ }^{1, *}$
}

Editorial Among the global responses to COVID-19, Sweden's response has received both praise and criticism for the implementation of certain measures. This paper, provided by Public Health Agency Sweden's Director General Johan Carlson and State Epidemiologist Anders Tegnell, describes the main goals of Sweden's public health response: minimizing transmission, mortality, and morbidity; minimizing other negative health effects and externalities of the pandemic; and safeguarding essential services in the society. While some of the stances or strategies described may differ from China CDC's recommendations or other measures adopted in China, China CDC Weekly seeks to act as a platform for global voices to disseminate and discuss a variety of viewpoints to achieve an improved, mutual understanding of our counterparts.

\section{INTRODUCTION}

Sweden had its first confirmed case of coronavirus disease 2019 (COVID-19) at the end of January 2020. Sweden's response to COVID-19, despite having the same objectives and goals as other countries, has received global attention with both praise and criticism. The main goals for Sweden's response has been to slow the spread of COVID-19, minimize mortality and morbidity in the entire population, minimize other negative health effects of the pandemic, and to safe guard essential services of society. The major elements of the public health response will be described briefly here without aspiring to give a comprehensive overview of the overall strategy.

\section{POPULATION HEALTH AND THE HEALTHCARE SYSTEM IN SWEDEN}

Sweden has a total population of 10 million. The general health of the population is good with life expectancies of 81.3 years for males and 84.7 years for females; low maternal and child mortality rates; and a demographic distribution with $20 \%$ of the population $>65$ years (1). Sweden has highly-subsidized universal healthcare coverage. Management of the healthcare system, including communicable disease response, is decentralized to 21 regions. The Public Health Agency coordinates communicable disease response nationally and has a broad mandate for public health, including prevention and control of non-communicable diseases and support for mental health and health equity. Government expert agencies in Sweden have strong mandates at the national level to inform policy; trust among the general population in government institutions and the healthcare system is fairly high (2).

\section{THE COVID-19 OUTBREAK IN SWEDEN}

Sweden had a massive introduction of the virus in February 2020, particularly in Stockholm, and not only from the Alps. During the February winter break, approximately 1 million Swedes travelled abroad, mainly from the Stockholm area. Genome sequencing of COVID-19 virus showed that the virus introduced into Sweden belonged to 3 distinct genetic groups, supporting the hypothesis that there were several separate, parallel introductions early in the pandemic (3).

Up to September 14, 5,846 people have died from COVID-19 in Sweden (2,650 females and 3,196 males) (4). Most deaths have been among individuals over 70 years, and the Stockholm region has been the most affected. Deaths among elderly people in nursing homes represent a high proportion of COVID-19 fatalities. There has been a significant decline in new cases and severe cases during the summer following a peak in late March and early April. Currently, the number of confirmed cases and the ratio of confirmed cases to the number of tests performed has declined, and various assessments show a decline in transmission and numbers of individuals infected. The national incidence of COVID-19 between August 31 and 
September 6, 2020 was 13 cases per 100,000 inhabitants (4).

There are complex reasons for the high number of fatalities in Sweden compared with neighboring countries, and the impact of several factors needs to be considered when comparing mortality rates. These factors include important differences in the epidemiology of the pandemic and structural differences in demographics and the healthcare system. The management of the pandemic, the role and impact of different response measures, compliance with binding and voluntary measures, and other health effects are also essential considerations for understanding the high number of fatalities.

Population immunity has never been the goal of the Swedish strategy. Immunity has proven to be difficult to estimate due to heterogeneous spread of the virus. The most recent serological survey was conducted in June and showed that $18.7 \%$ (95\% CI: $14.8 \%-23.3 \%$ ) of people living in a highly affected area had antibodies to COVID-19 virus, and that nationwide, approximately $7 \%$ of the population had antibodies, with substantial variation by age group and region.

\section{PUBLIC HEALTH RESPONSE TO COVID-19 IN SWEDEN}

The Communicable Disease Act (2004:168) of Sweden guides overall responses to communicable disease threats; the responsibility of individuals in minimizing disease transmission is articulated in the Act. Sweden's main public health response has been to minimize transmission as much as possible and to protect risk groups, particularly the population above 70 years of age (5). Currently, Sweden has a high capacity for contact tracing and testing, including preparedness for early detection and management of new cluster outbreaks. The initial strategy of strict containment changed to mitigation and protection of risk groups on March 10, when the pandemic had become widespread across society. As testing capacity increased and the number of new cases decreased, testing and contact tracing has been scaled up significantly.

\section{A COMBINATION OF BINDING RULES AND RECOMMENDATIONS}

Sweden has developed a response package that includes both legally binding regulations and strong but voluntary recommendations. The government passed a ban on gatherings of over 50 people. Travel has been restricted on and off, and recommendations to avoid unnecessary travel have been issued. International travel was restricted by the Ministry of Foreign Affairs, including an entry ban for nonessential travel to Sweden from countries outside the EU until June 15 and advice against non-essential travel to all countries through July 15. From March 19 to May 13, the recommendation was to avoid unnecessary domestic travel. Subsequently, 2-hour trips were allowed for asymptomatic persons, and from June 12, domestic travel was again permitted under the condition that other recommendations were adhered to. Employers have been responsible for adapting workplaces to prevent the spread of infection. Distanced education has been implemented in secondary schools and universities. Visits to nursing homes were banned on April 1, and assignments were given to providers of long-term care to develop safe measures in which nursing home residents can meet with family and friends. The ban will be lifted on October 1, 2020.

Legally binding rules have been supplemented with recommendations and guidelines to facilitate compliance with recommendations, such as staying at home even with the slightest symptom of an infection, physical distancing, enhanced hygiene measures, avoiding public transportation, and working from home if possible. There have been strong recommendations for people in risk groups and individuals over 70 years of age to limit close contacts as much as possible.

\section{TEMPORARY CHANGES IN THE SOCIAL SECURITY SYSTEM}

The government made temporary changes in sickness insurance so that employees can stay at home from the very first day of symptoms without financial consequence. The requirement of a medical certificate for sick leave $>7$ days was temporarily removed to facilitate sick leave and home quarantine.

\section{PRIMARY SCHOOLS HAVE REMAINED OPEN}

Schools have been open for healthy children under 16 years of age. The rationales behind that decision were that children were not believed to be important 
drivers of the pandemic, that closing schools has negative health consequences, and that children rarely get seriously ill from COVID-19. Children have the same recommendations as does the general public e.g. avoiding large public gatherings, adhering to hand hygiene, and staying at home if symptomatic. Keeping primary schools open, thus far, has not generated an increase in transmission (G).

\section{COMMUNICATION AND COMPLIANCE}

Together with the National Board of Health and Welfare and the Swedish Civil Contingencies Agency, the Public Health Agency has held daily press conferences with new and updated regulations and recommendations, including the latest epidemiological information about the pandemic. Special effort has been made to inform underserved communities. Communications have been a central component of the response.

Aspects of compliance and behavioral changes of the public have been monitored repeatedly through webbased questionnaires. Monitoring includes the number of contacts and physical distancing measures. Travel patterns have been monitored with mobile phone data. The Swedish population has adjusted its behavior to a large extent.

\section{PROTECTIVE GEAR}

Medical face masks and other protective gear are considered by the Public Health Agency to be absolutely essential in healthcare facilities. Compliance with recommendations on physical distancing and the currently low level of spread in Swedish society, in combination with the still rather weak evidence of the effectiveness of public use of different kinds of face masks, has not yet prompted a recommendation for public use of face masks. However, if and

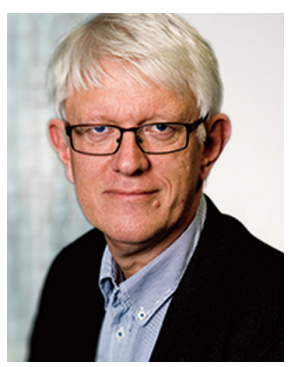

Dr. Johan Carlson, MD, PhD, Director General of Public Health Agency Sweden when transmission increases, face masks will be considered - for example, in settings where physical distancing cannot be maintained.

\section{DISCUSSION}

The Swedish COVID-19 strategy has focused on minimizing transmission and protecting of risk groups while at the same time trying to mitigate other public health threats. Compliance with rules, recommendations, and advice is estimated to have been satisfactory so far, and the combination of binding and voluntary response measures seem to have had an effect. The reasons for high fatality rates in Sweden, when compared to neighboring countries, is complex and cannot be explained by the nature of the Swedish response alone.

doi: $10.46234 / \mathrm{ccdcw} 2020.215$

\# Corresponding author: Anders Tegnell, anders.tegnell@folkhal somyndigheten.se.

${ }^{1}$ Public Health Agency Sweden, Solna, Sweden.

Submitted: September 22, 2020; Accepted: September 28, 2020

\section{REFERENCES}

1. Statistics Sweden. Population statistics. https://www.scb.se/en/findingstatistics/statistics-by-subject-area/population/population-composition/ population-statistics/. [2020-08-19].

2. Strategy in response to the COVID-19 pandemic. https://www.govern ment.se/articles/2020/04/strategy-in-response-to-the-covid-19pandemicl. [2020-04-06].

3. Helgenomsekvensering av svenska SARS-CoV-2 som orsakar COVID19, del 2 (Whole Genome Sequencing of Swedish SARS-CoV-2 that cause COVID-19, part 2). https://www.folkhalsomyndigheten.se/publi cerat-material/publikationsarkiv/h/helgenomsekvensering-av-svenskasars-cov-2-som-orsakar-covid-19-del2/. [2020-07-01].

4. Confirmed cases in Sweden - daily update. https://ahenforadiodk. com/confirmed-cases-in-sweden-daily-update/. [2020-06-13].

5. COVID-19 - The Swedish strategy. https://www.folkhalsomyndigheten. se/the-public-health-agency-of-sweden/communicable-diseasecontrol/covid-19--the-swedish-strategy/. [2020-07-03].

6. Covid-19 in schoolchildren - A comparison between Finland and Sweden. https://www.folkhalsomyndigheten.se/publicerat-material/publi kationsarkiv/c/covid-19-in-schoolchildren/. [2020-07-07].

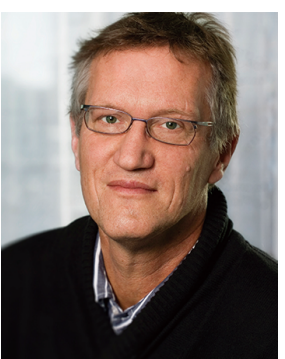

Dr. Anders Tegnell, MD, PhD, State Epidemiologist of Sweden, Public Health Agency Sweden 